\title{
Synthesis, Structure, and Reactivity of Gold(I) $\alpha$-Oxo Carbenoid Complexes
}

\author{
Caroline P. Stow and Ross A. Widenhoefer* \\ Duke University, Department of Chemistry, French Family Science Center, Durham, North \\ Carolina, 27708.
}

Supporting Information 
Figure S1: ${ }^{1} \mathrm{H}$ NMR spectrum of 1 a.

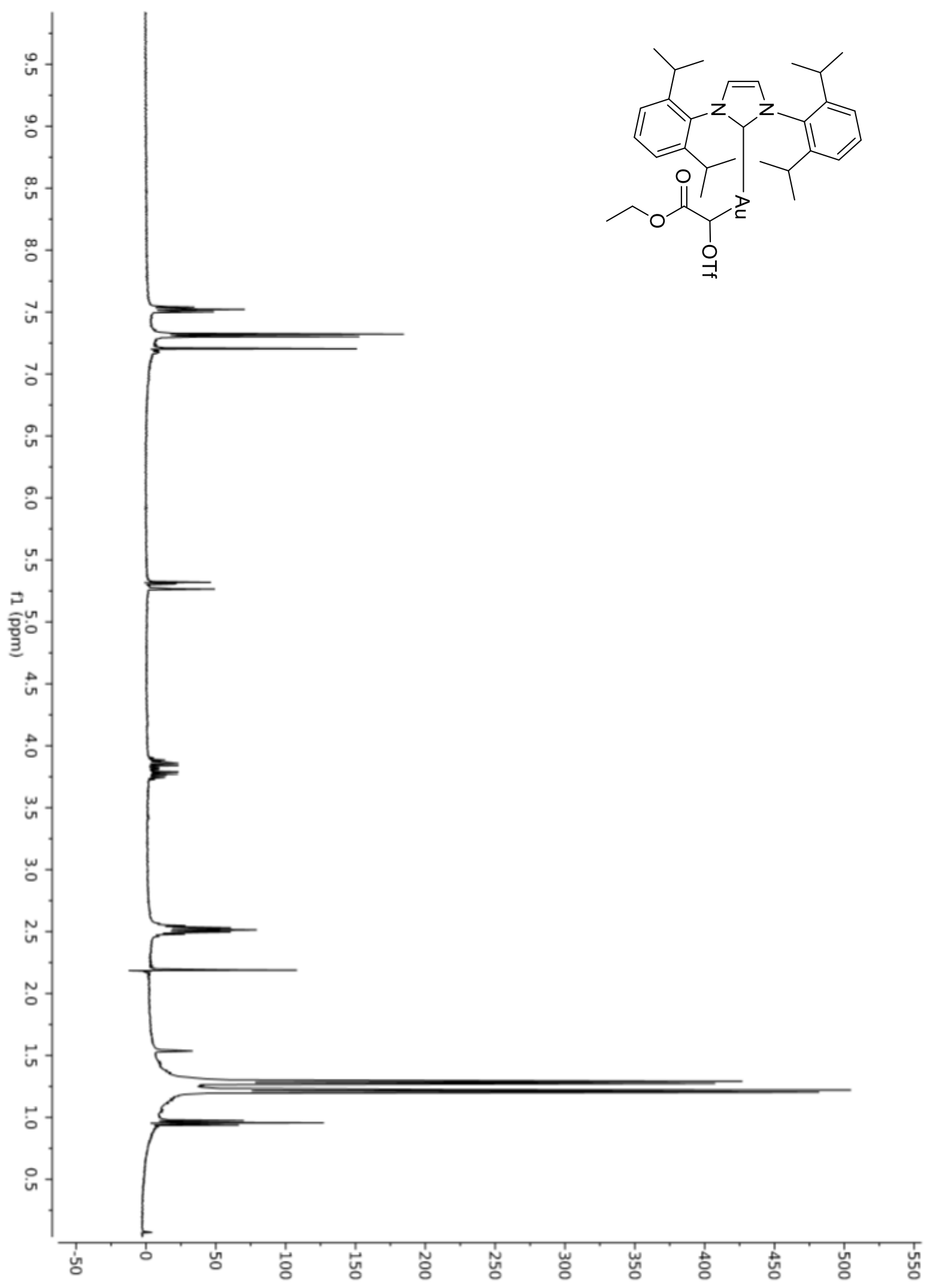




$$
E^{*}
$$


Figure S3: ${ }^{1} \mathrm{H}$ NMR spectrum of $\mathbf{1 b}$.

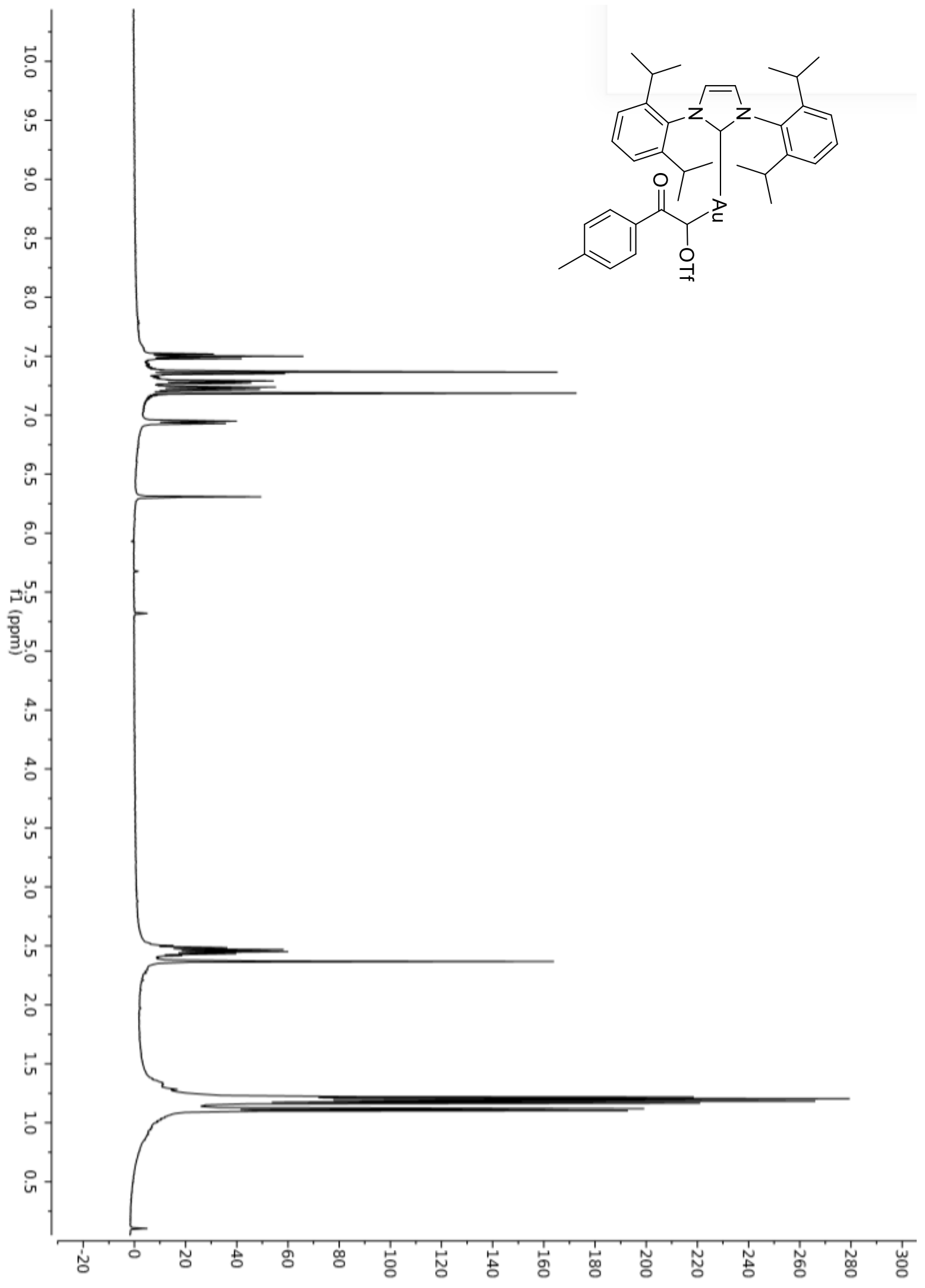


Figure S4: ${ }^{13} \mathrm{C}\left\{{ }^{1} \mathrm{H}\right\}$ NMR spectrum of $\mathbf{1 b}$.

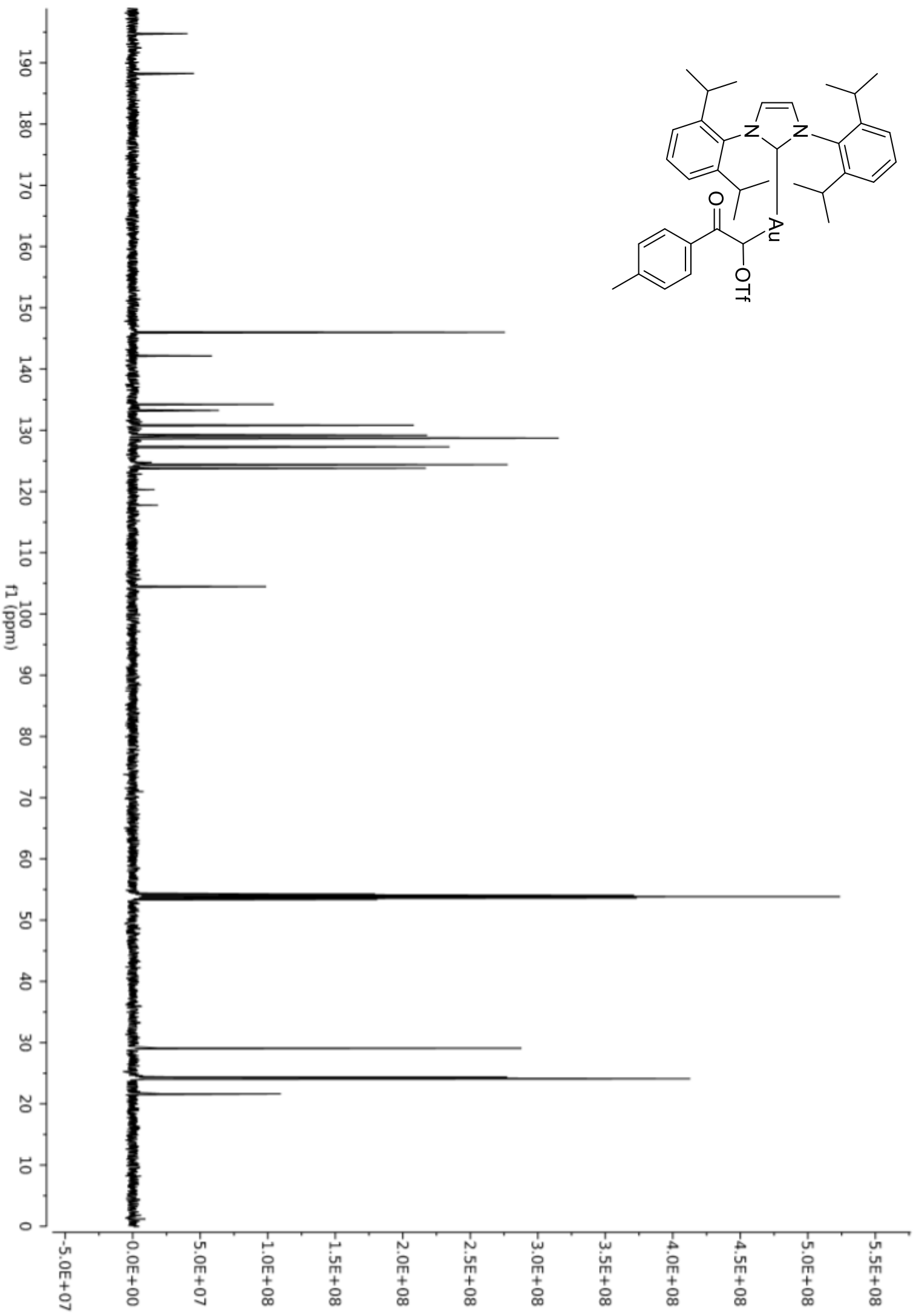

S 5 
Figure S5: ${ }^{1} \mathrm{H}$ NMR spectrum of $\mathbf{2 a}$.

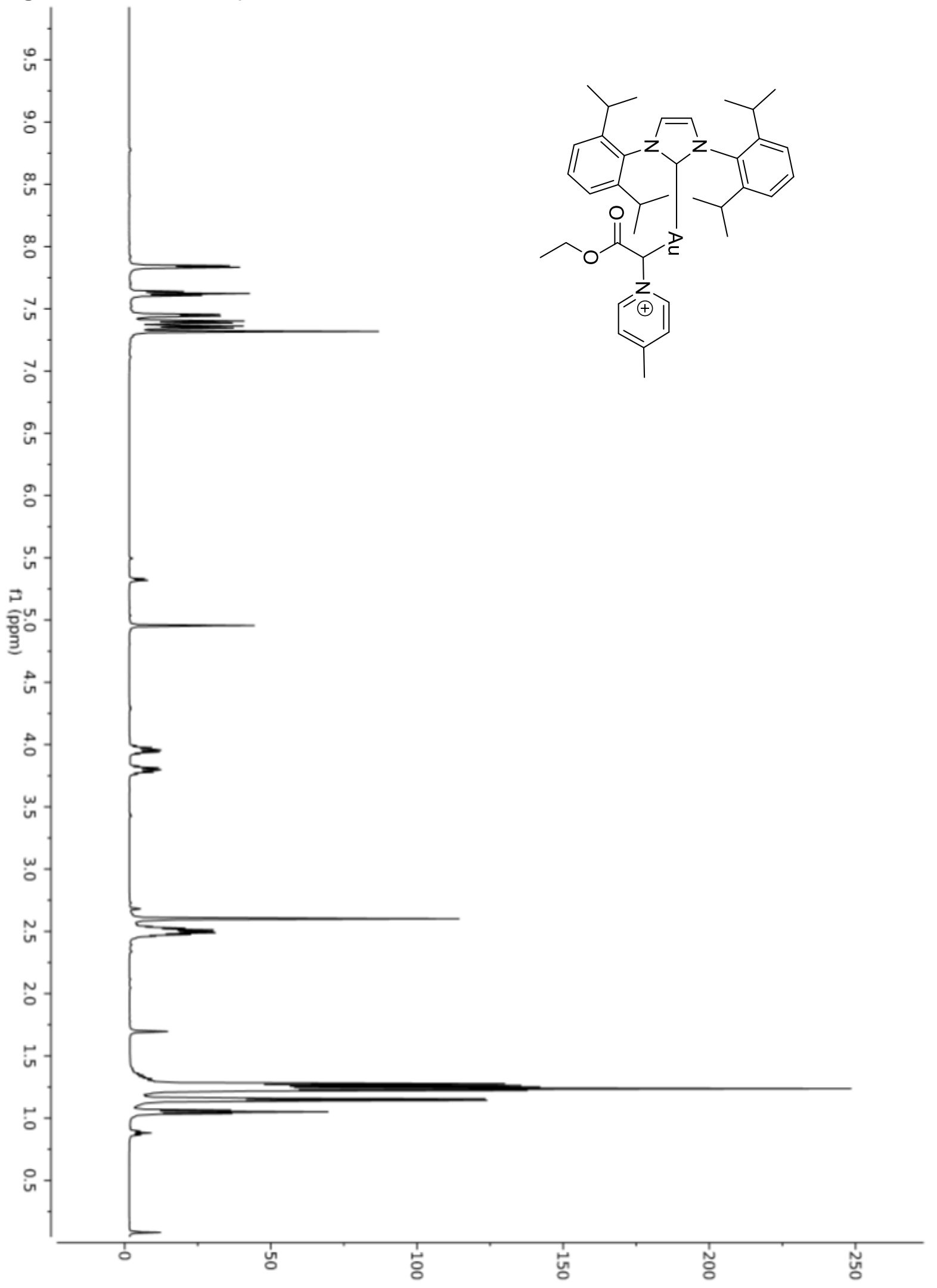


Figure S6: ${ }^{13} \mathrm{C}\left\{{ }^{1} \mathrm{H}\right\}$ NMR spectrum of $2 \mathrm{a}$.

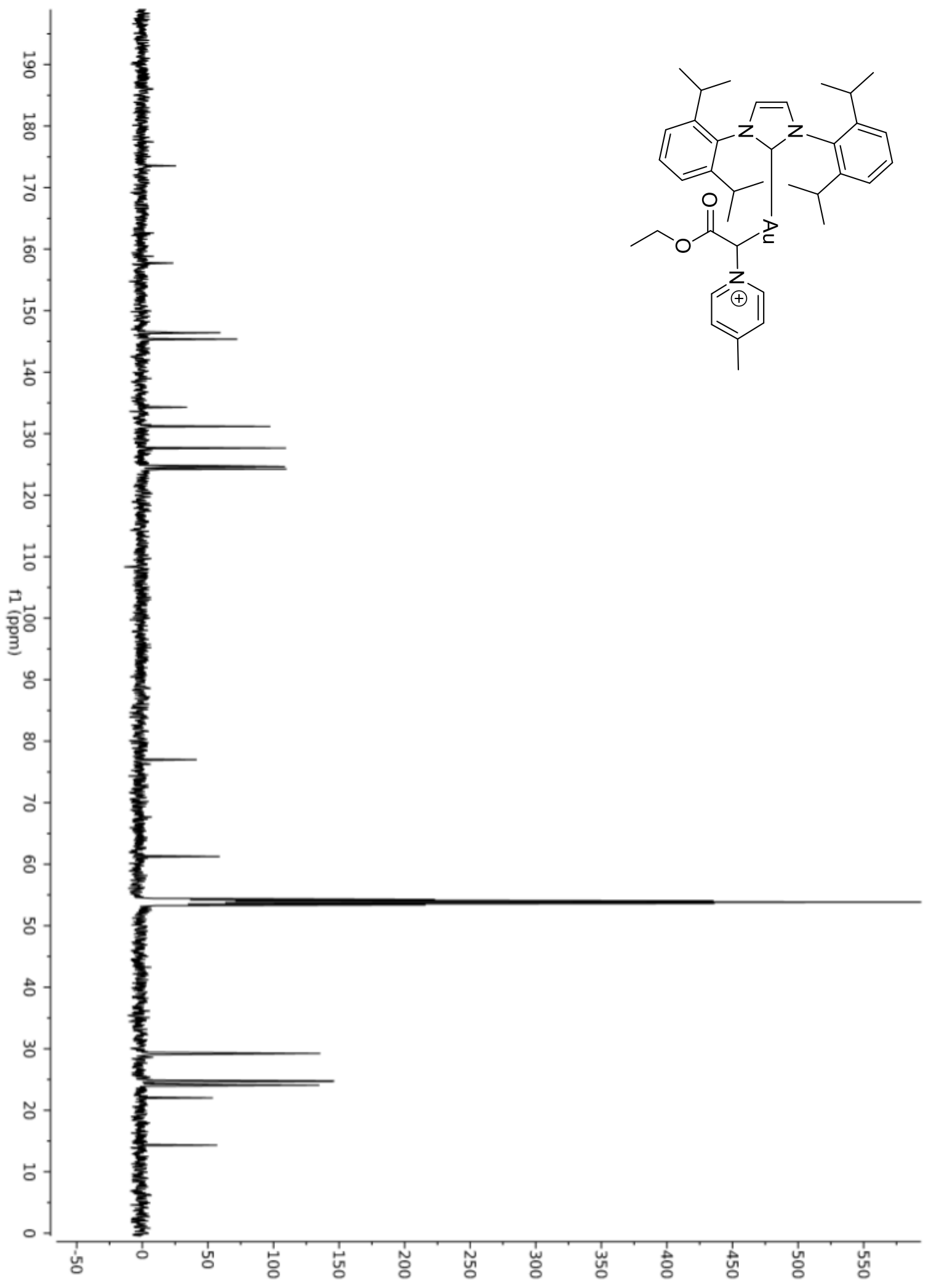


Figure S7: ${ }^{1} \mathrm{H}$ NMR spectrum of $\mathbf{2} \mathbf{b}$.

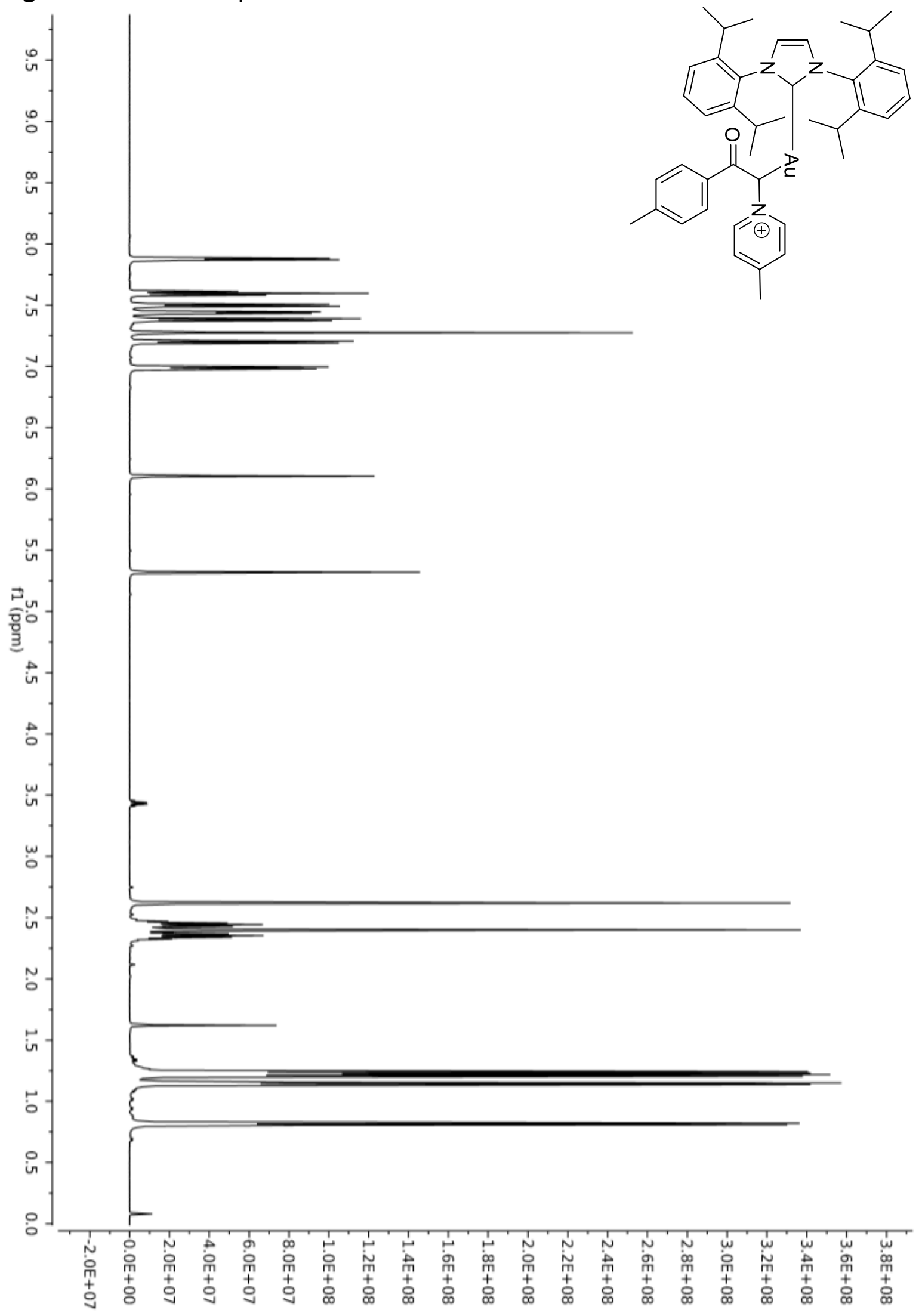


Figure S8: ${ }^{13} \mathrm{C}\left\{{ }^{1} \mathrm{H}\right\}$ NMR spectrum of $\mathbf{2 b}$.

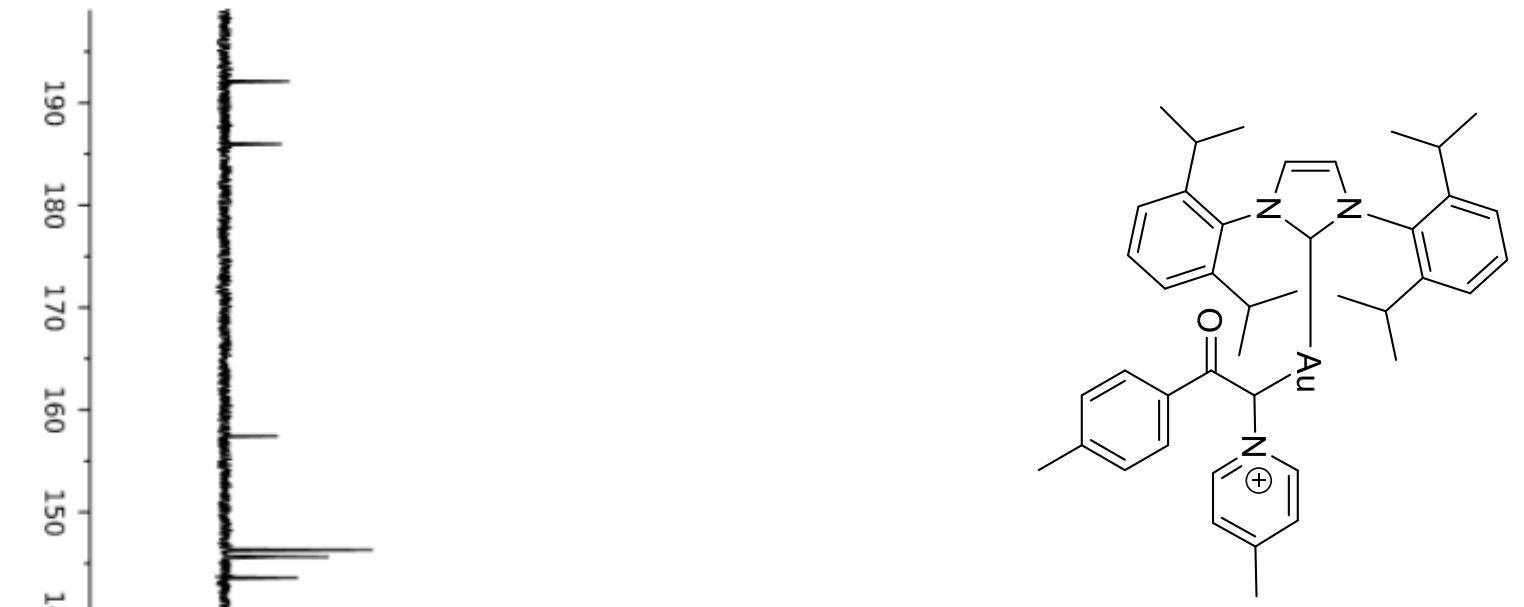


Figure S9: ${ }^{1} \mathrm{H}$ NMR spectrum of $\mathbf{3 a}$.

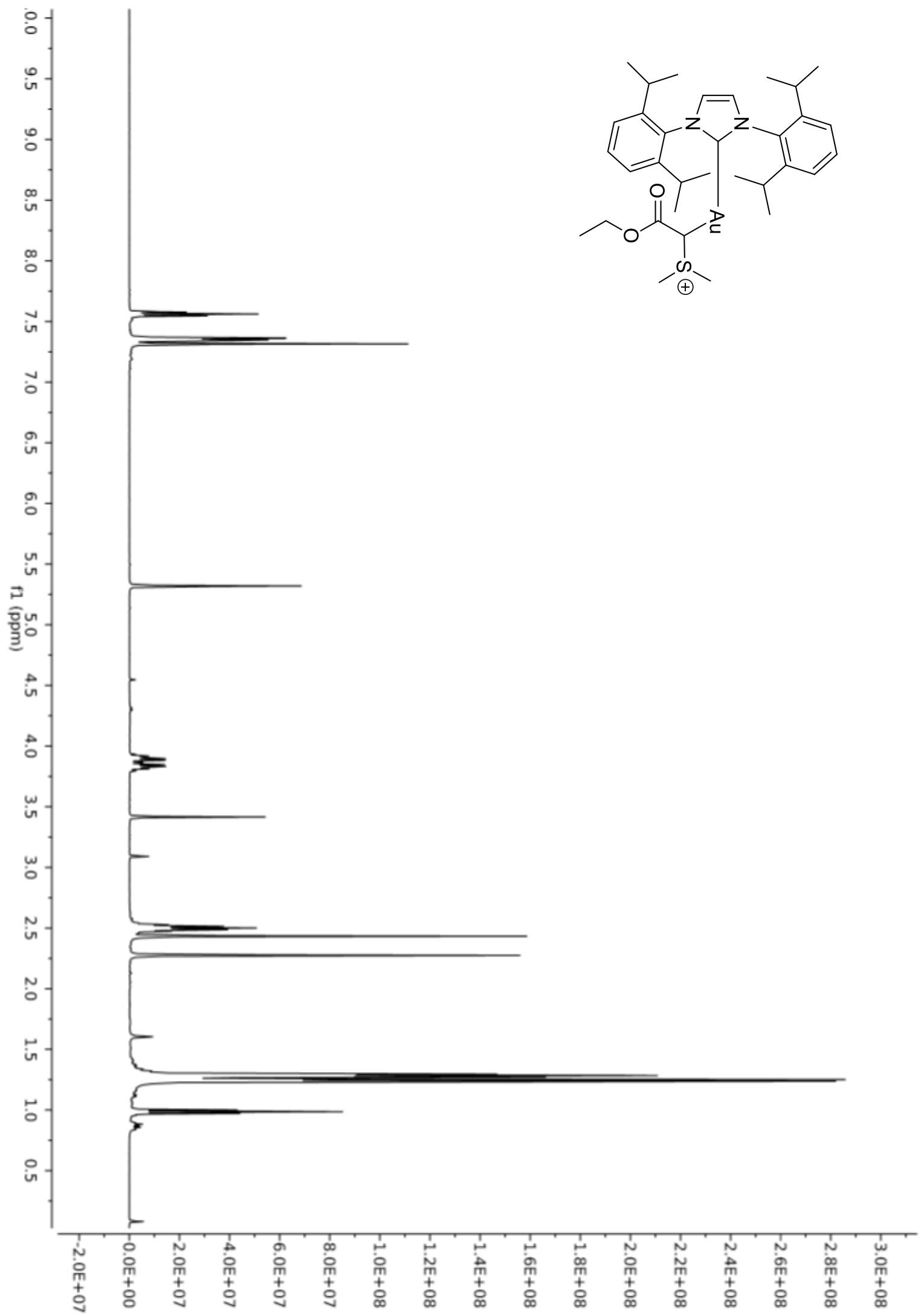


Figure S10: ${ }^{13} \mathrm{C}\left\{{ }^{1} \mathrm{H}\right\}$ NMR spectrum of $3 \mathbf{a}$.

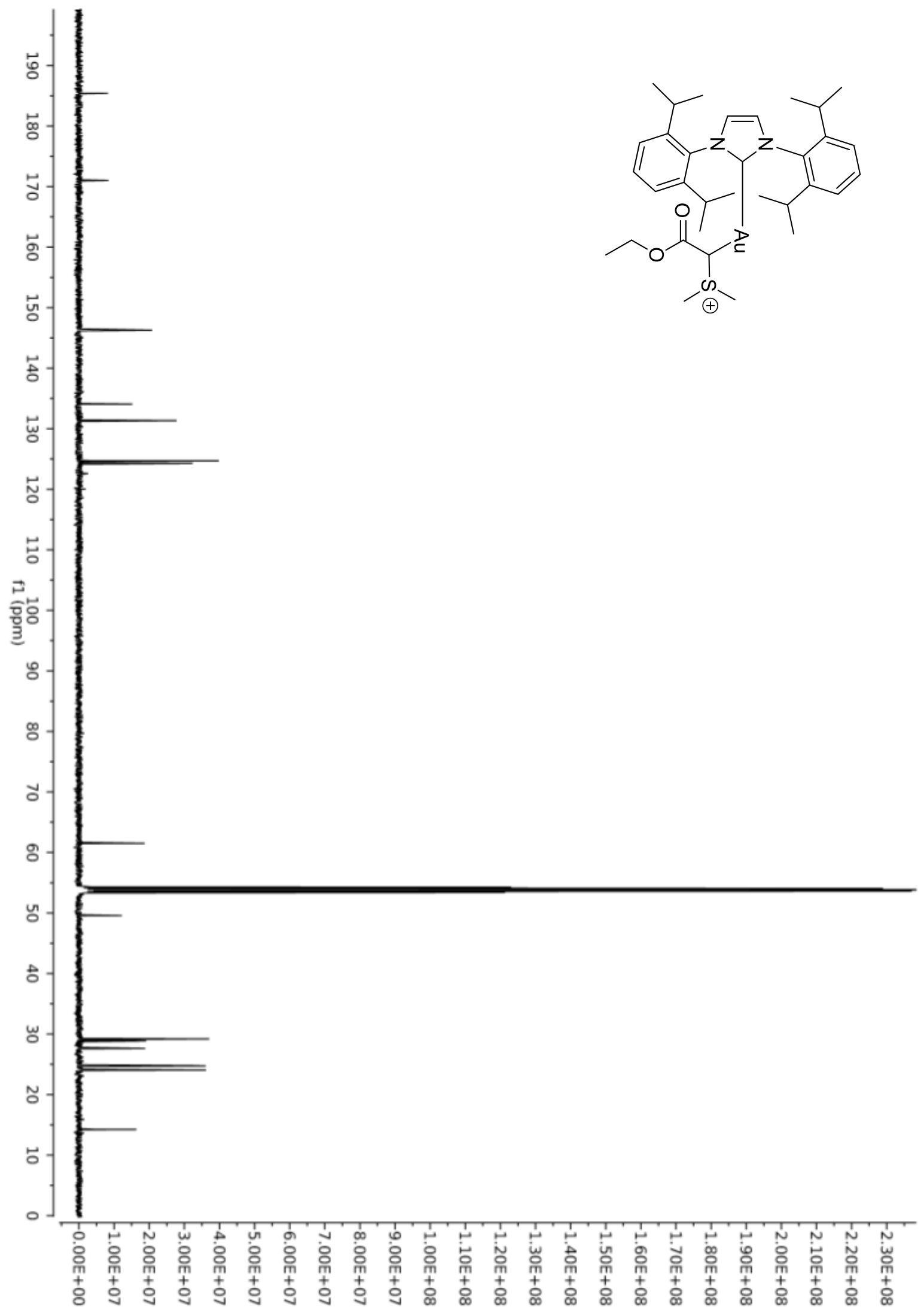


Figure S11: ${ }^{1} \mathrm{H}$ NMR spectrum of $\mathbf{3 b}$.

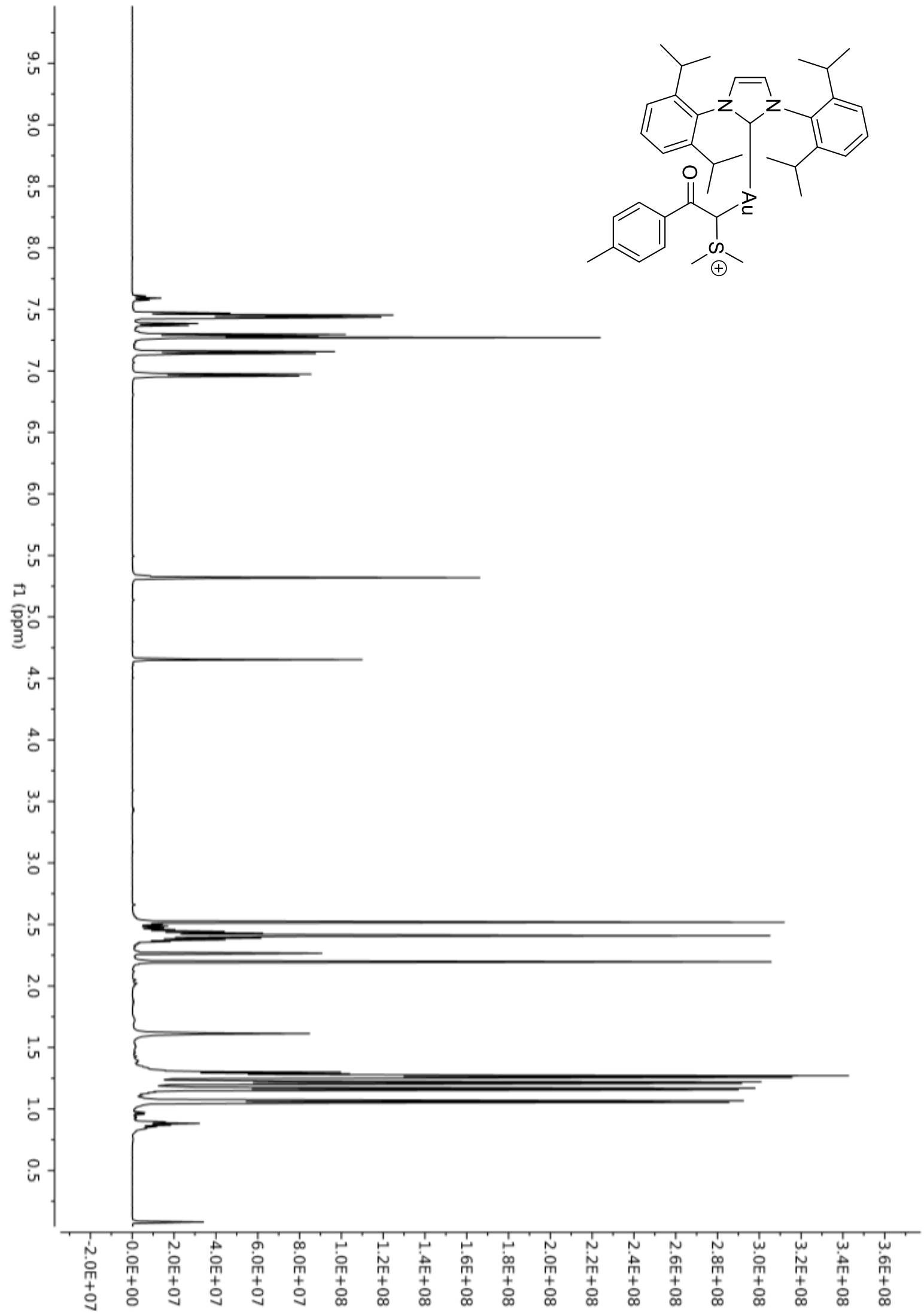


Figure S12: ${ }^{13} \mathrm{C}\left\{{ }^{1} \mathrm{H}\right\}$ NMR spectrum of $\mathbf{3 b}$.

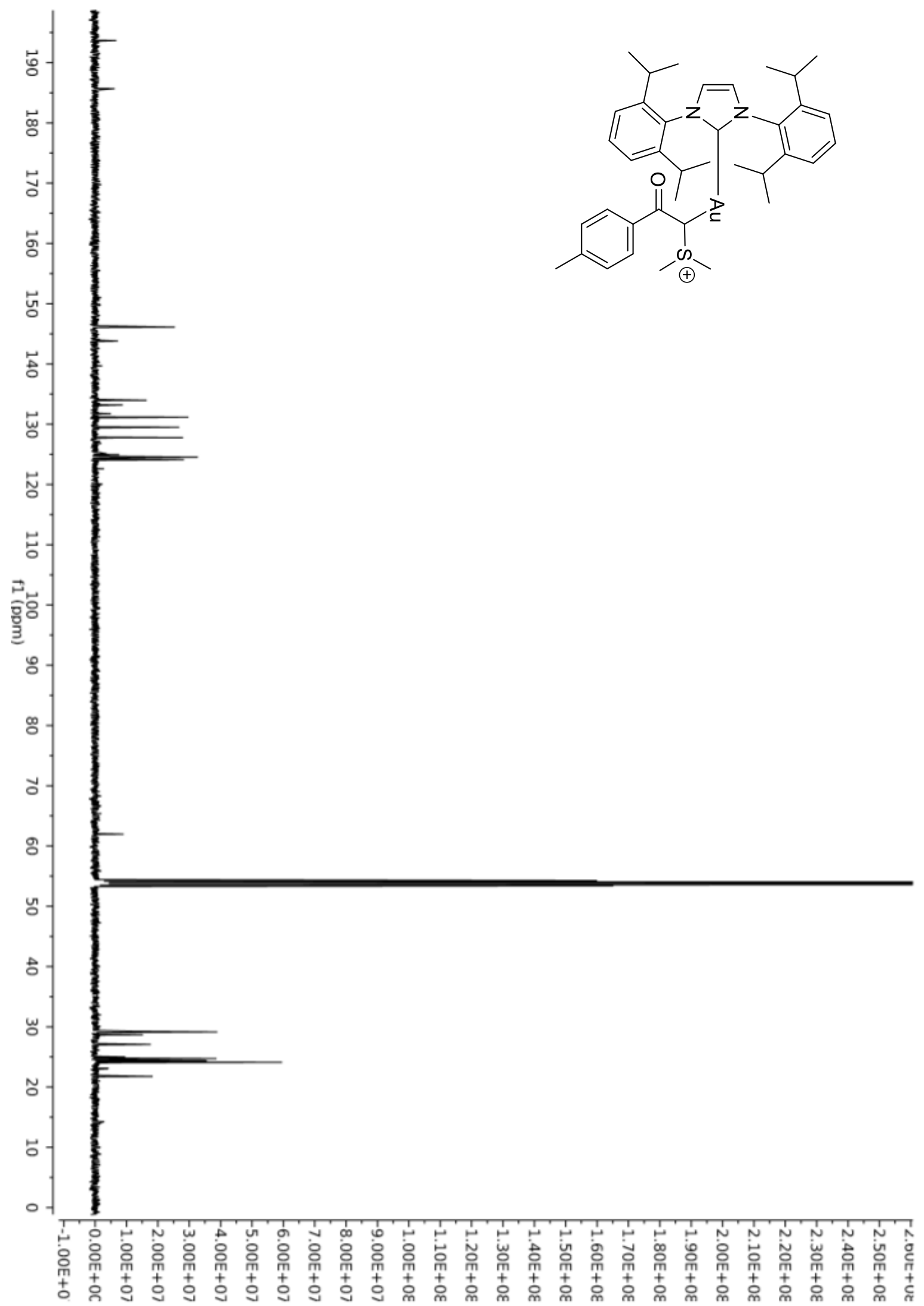


Figure S13: ${ }^{1} \mathrm{H}$ NMR spectrum of $4 a$.

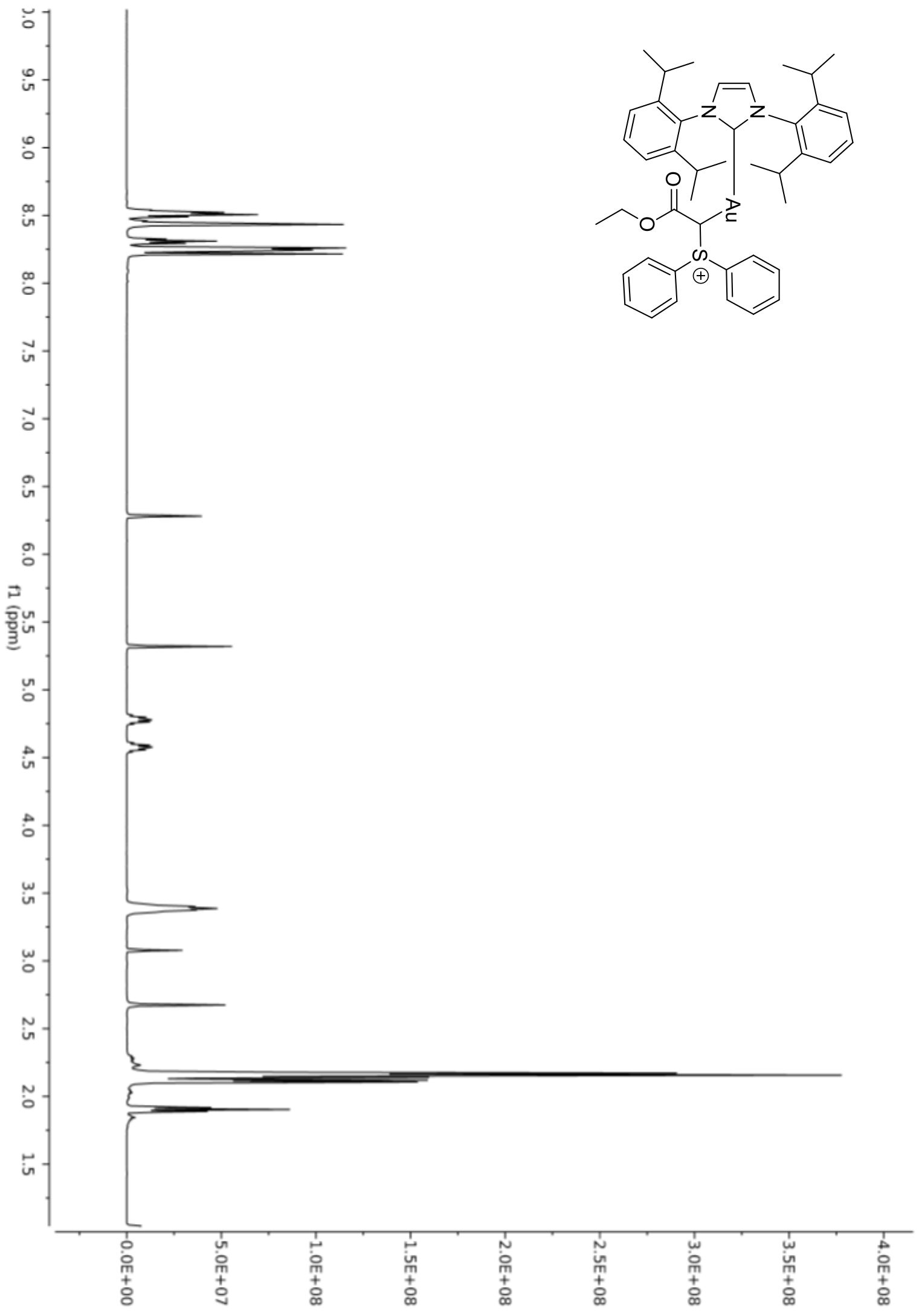


Figure S14: ${ }^{13} \mathrm{C}\left\{{ }^{1} \mathrm{H}\right\}$ NMR spectrum of $4 \mathrm{a}$.

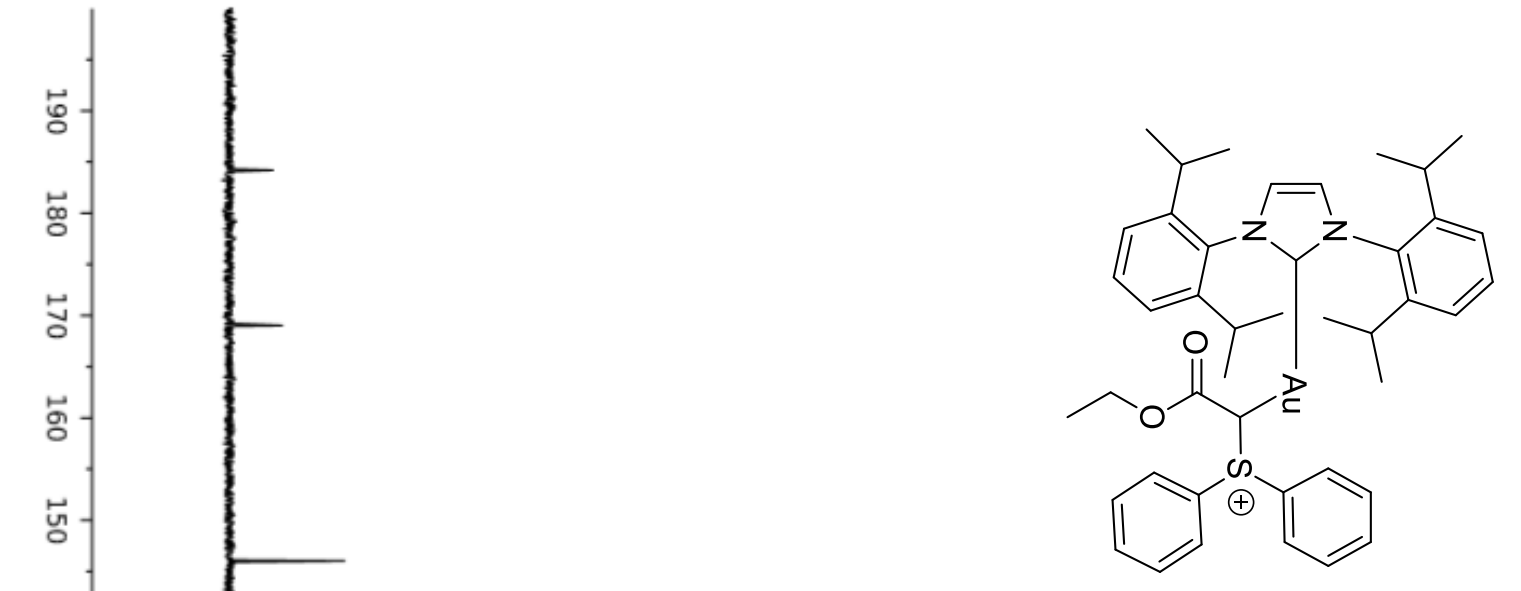

뭉

$$
8
$$

\section{8}

ธ

。

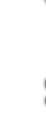

$$
\begin{aligned}
& \text { 능 }
\end{aligned}
$$

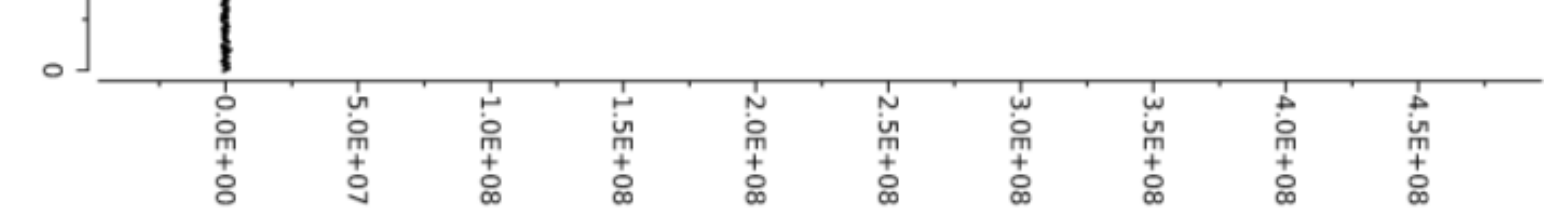


Figure S15: ${ }^{1} \mathrm{H}$ NMR spectrum of $\mathbf{4 b}$.

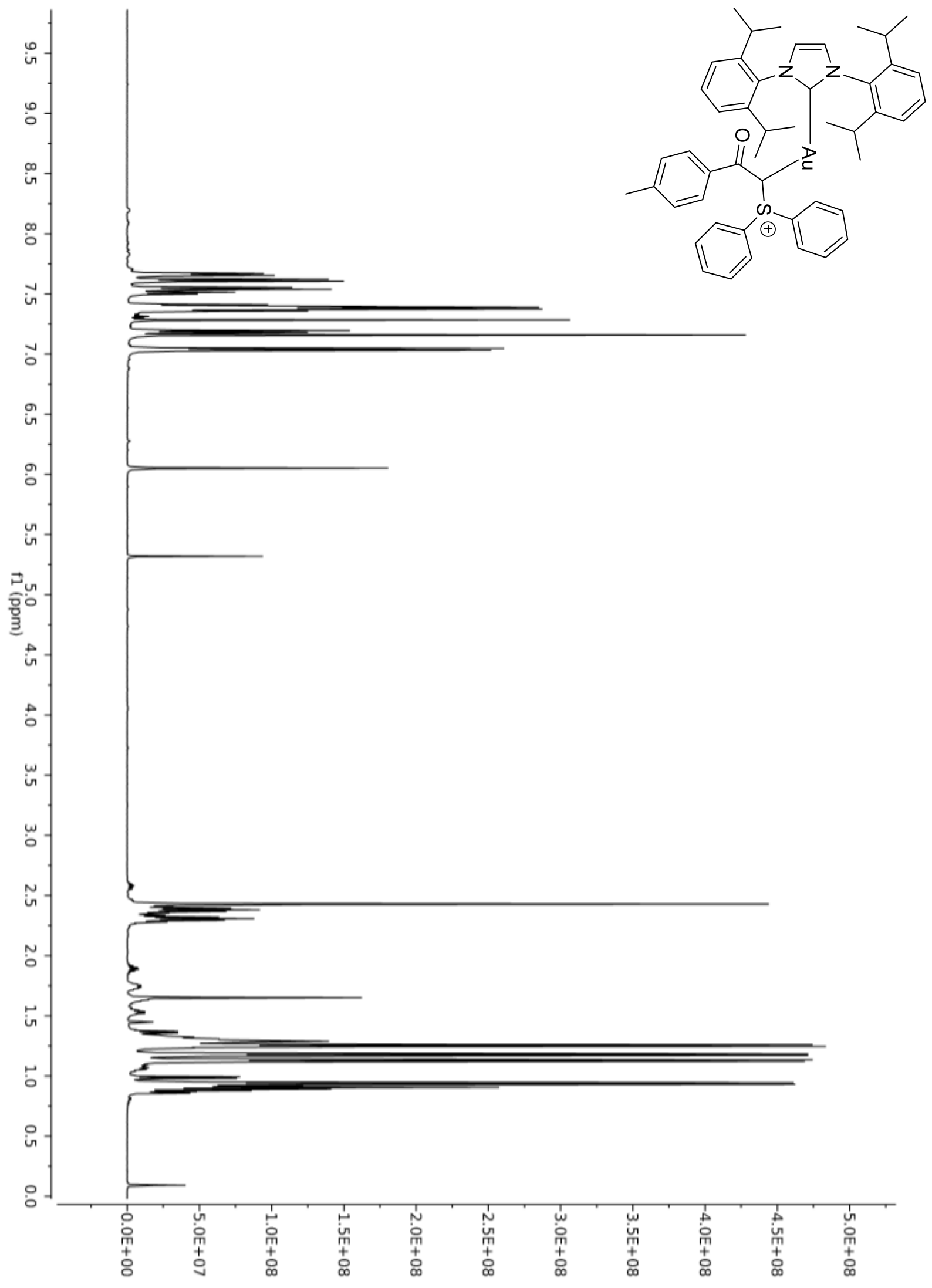


Figure S16: ${ }^{13} \mathrm{C}\left\{{ }^{1} \mathrm{H}\right\}$ NMR spectrum of $\mathbf{4 b}$.

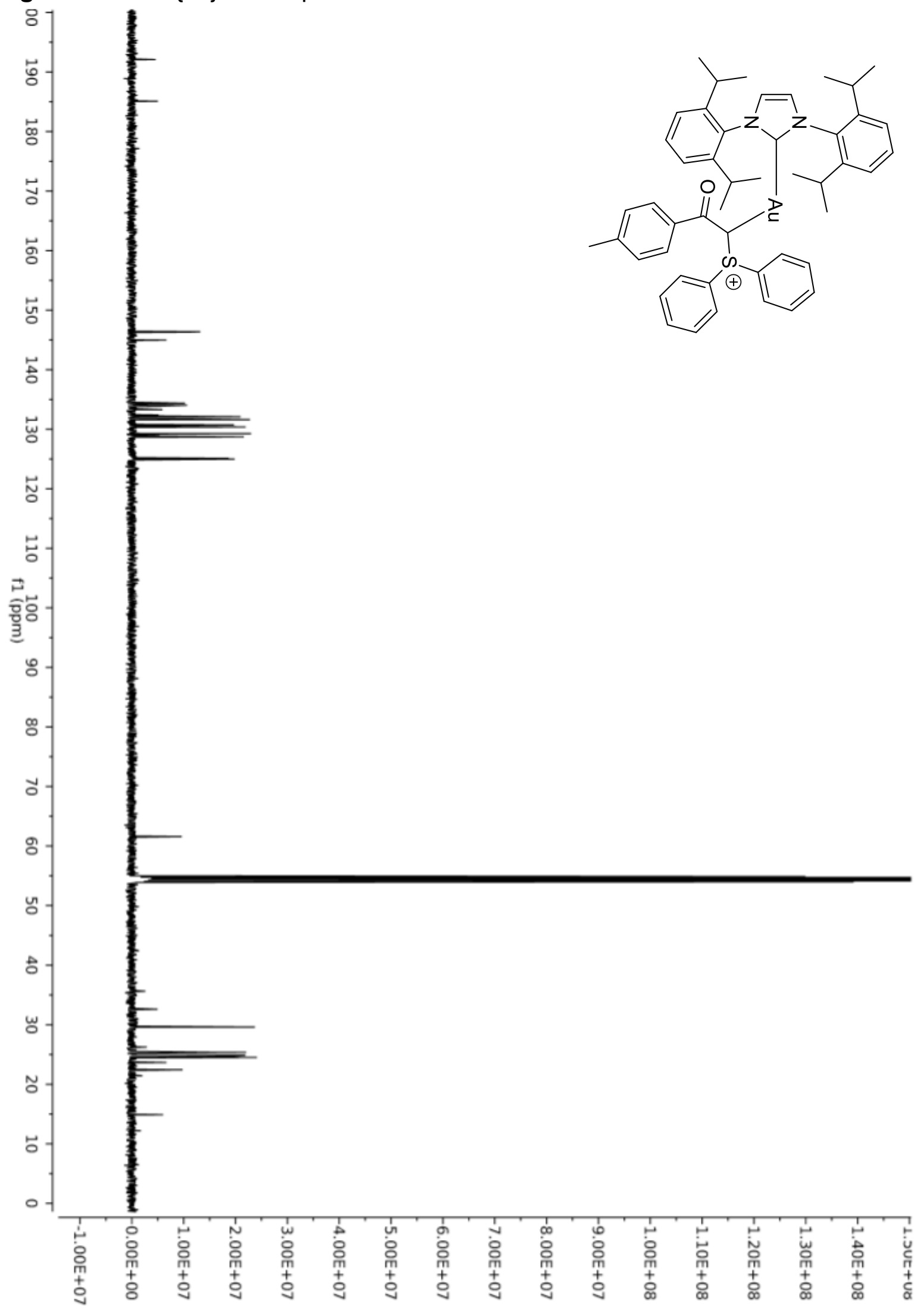

S 17 
Figure S17: ${ }^{1} \mathrm{H}$ NMR spectrum of 5.

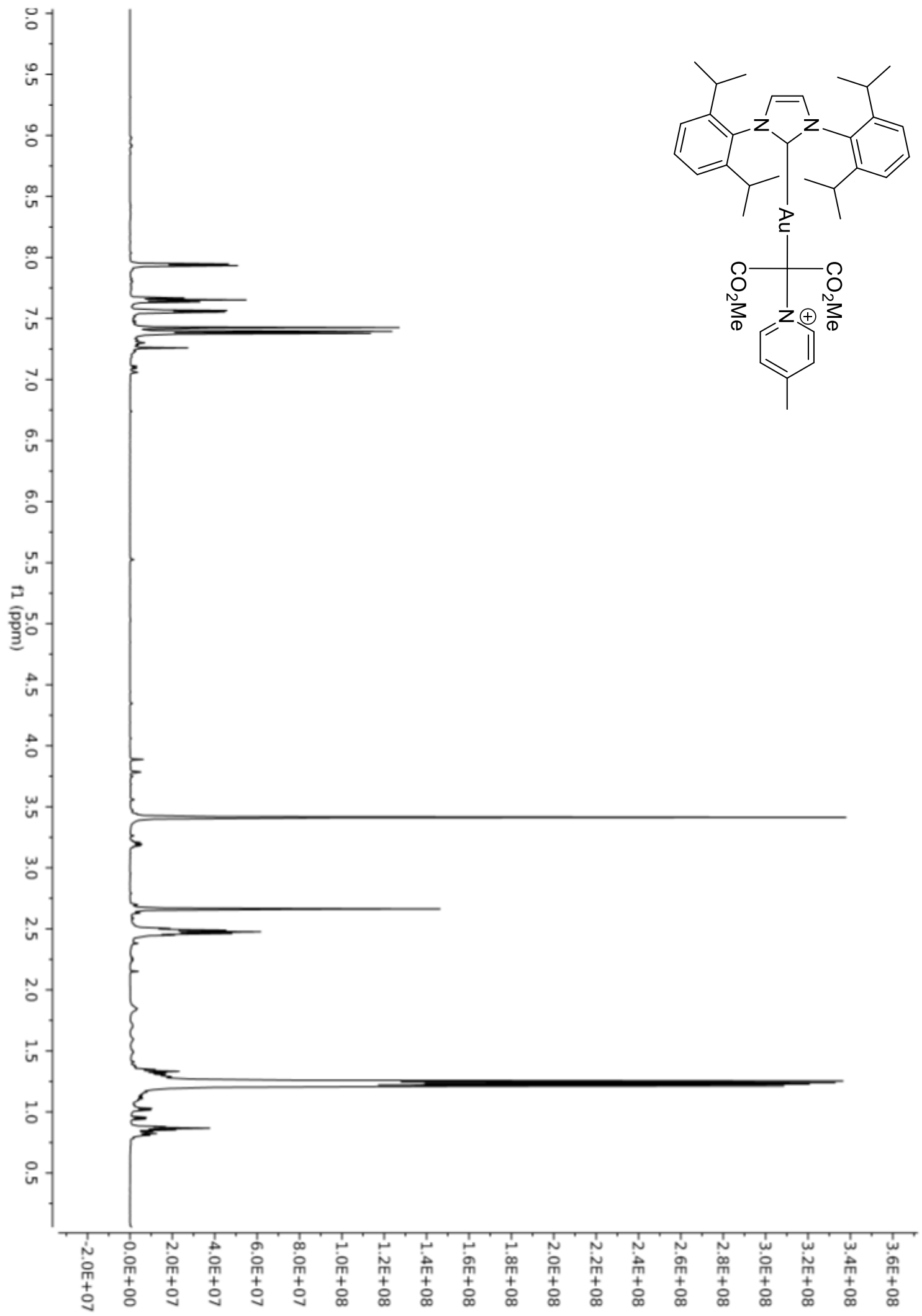


Figure S18: ${ }^{13} \mathrm{C}\left\{{ }^{1} \mathrm{H}\right\}$ NMR spectrum of 5.

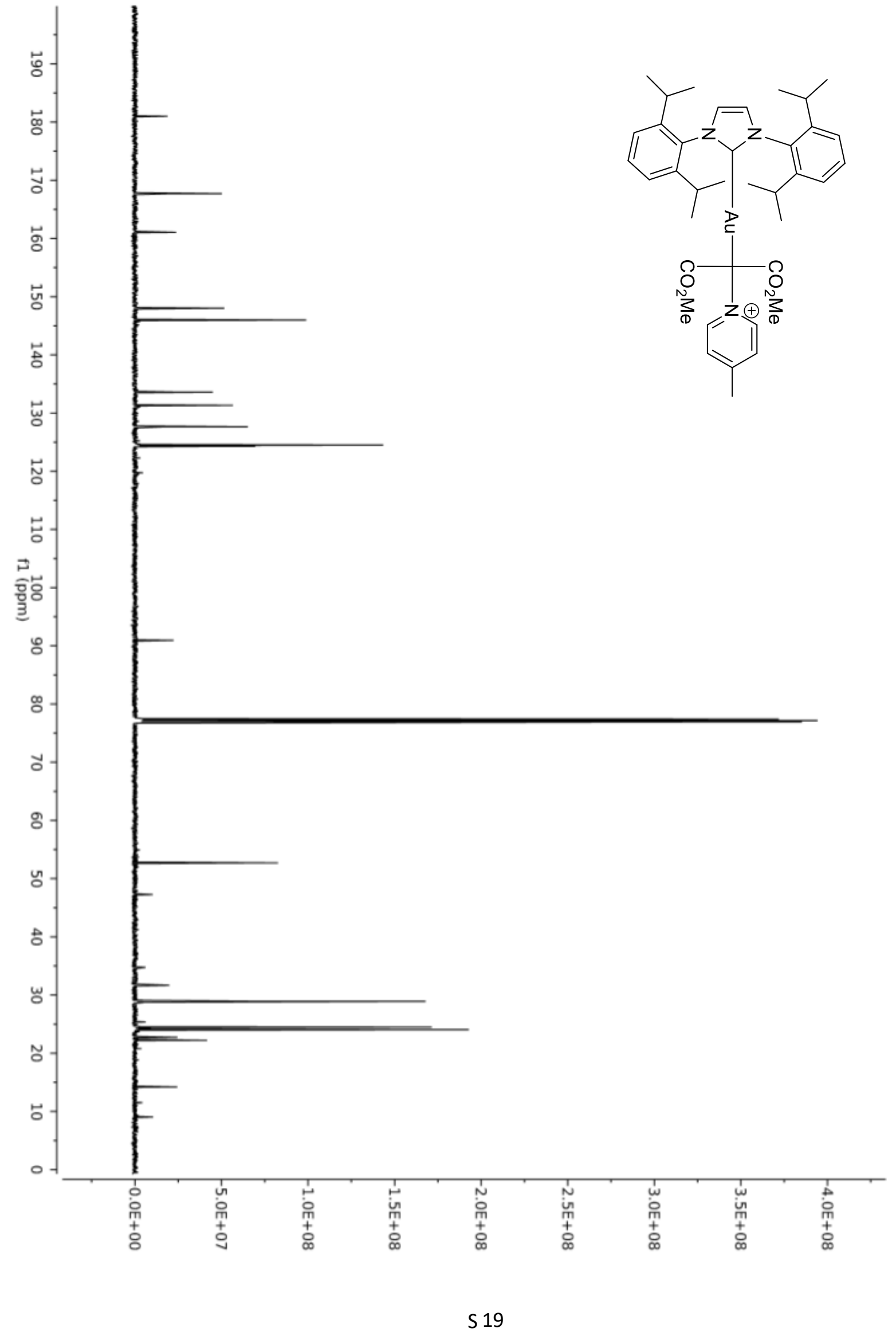


Figure S19: ${ }^{1} \mathrm{H}$ NMR spectrum of 6.

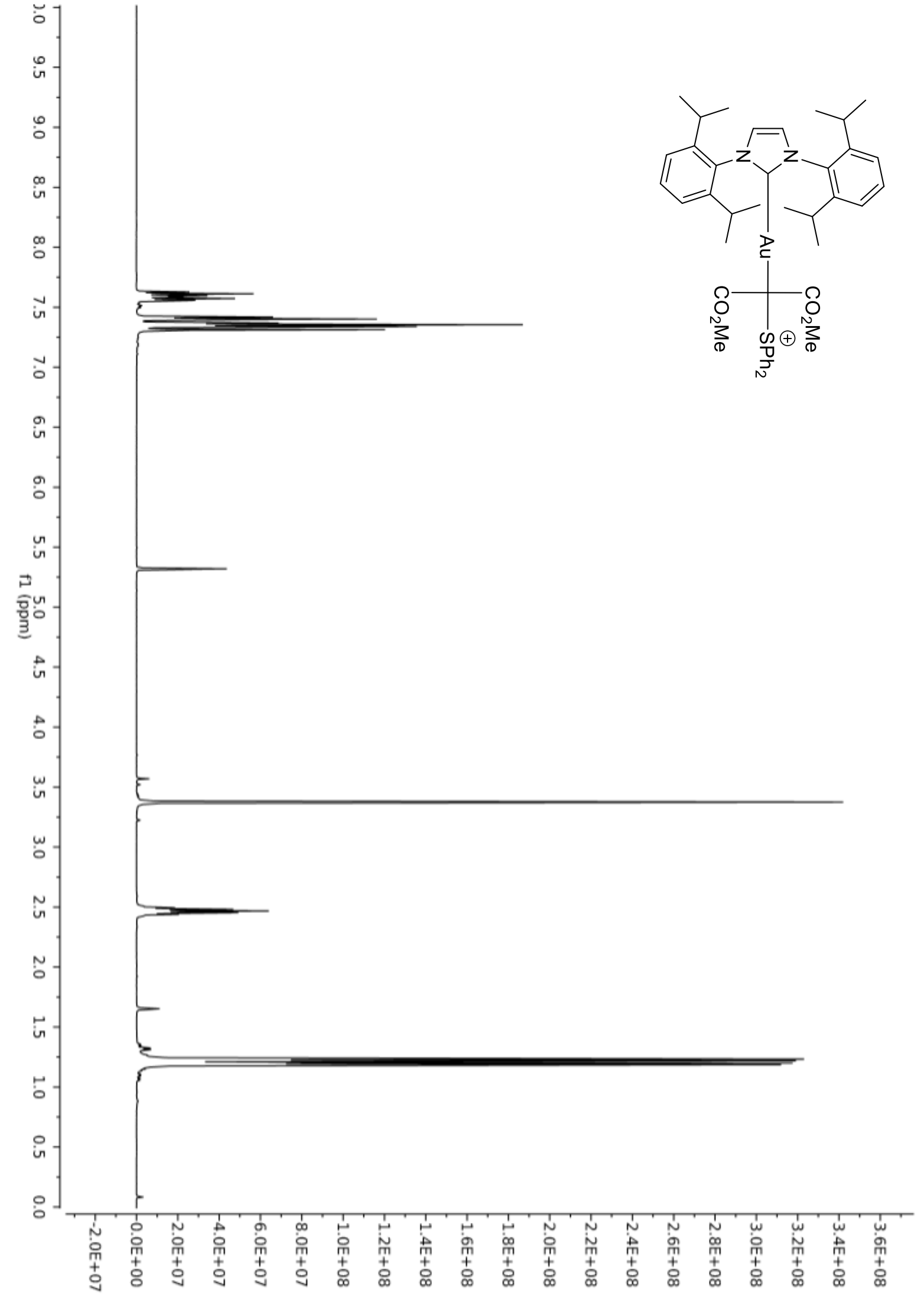


Figure S20: ${ }^{13} \mathrm{C}\left\{{ }^{1} \mathrm{H}\right\}$ NMR spectrum of 6 .
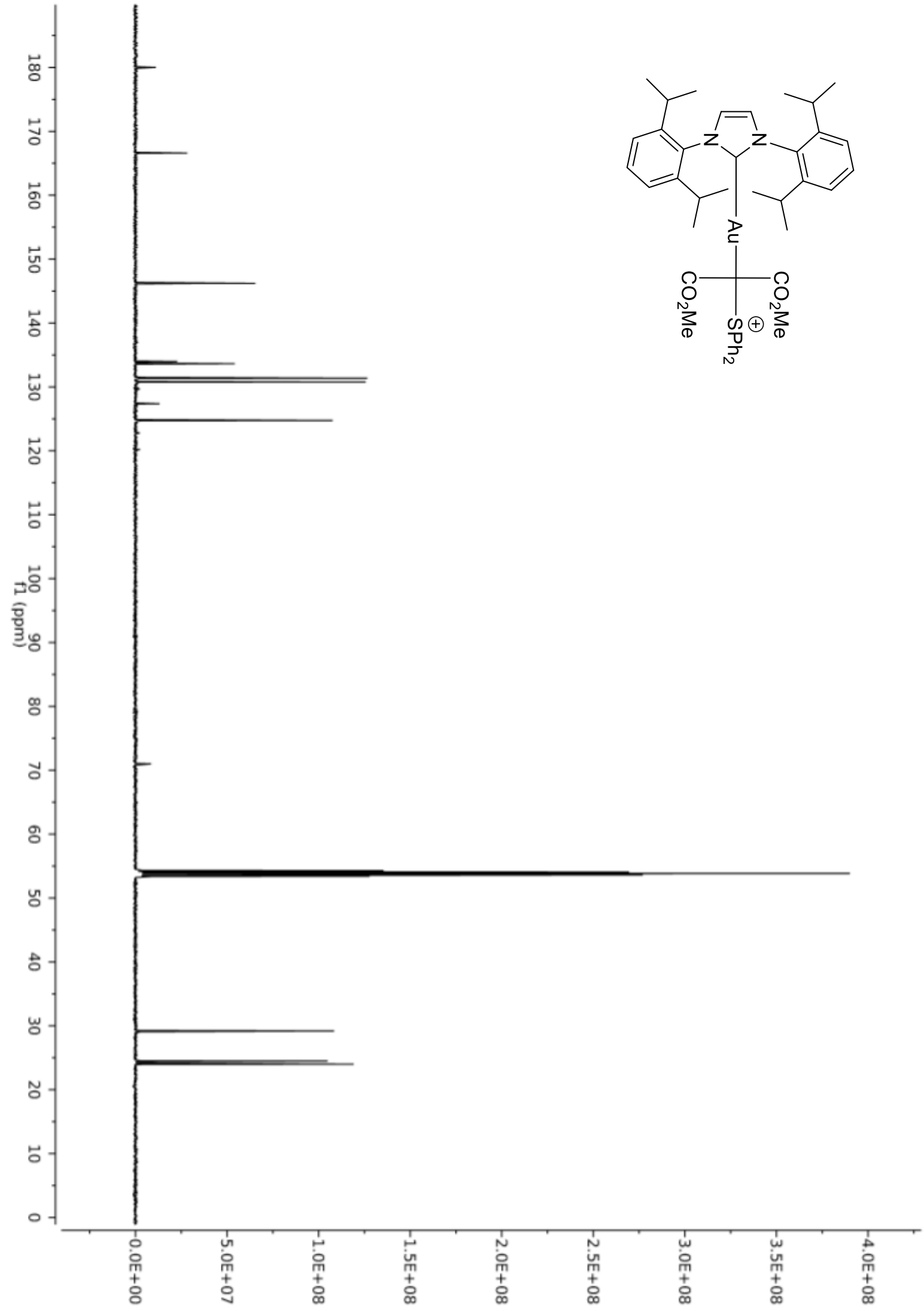
Figure S21: ${ }^{1} \mathrm{H}$ NMR spectrum of cis-7.

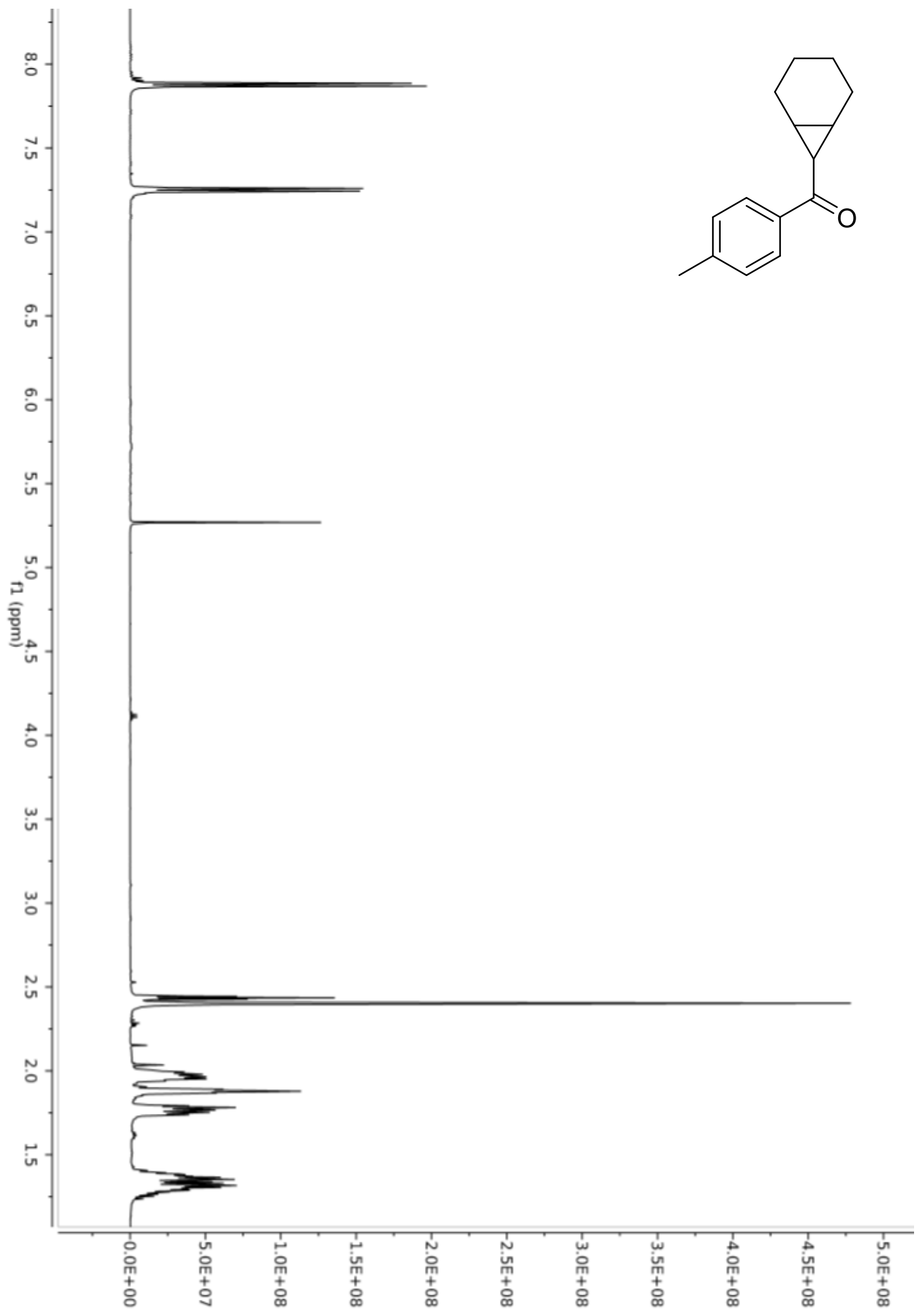


Figure S22: ${ }^{13} \mathrm{C}\left\{{ }^{1} \mathrm{H}\right\}$ NMR spectrum of cis-7.

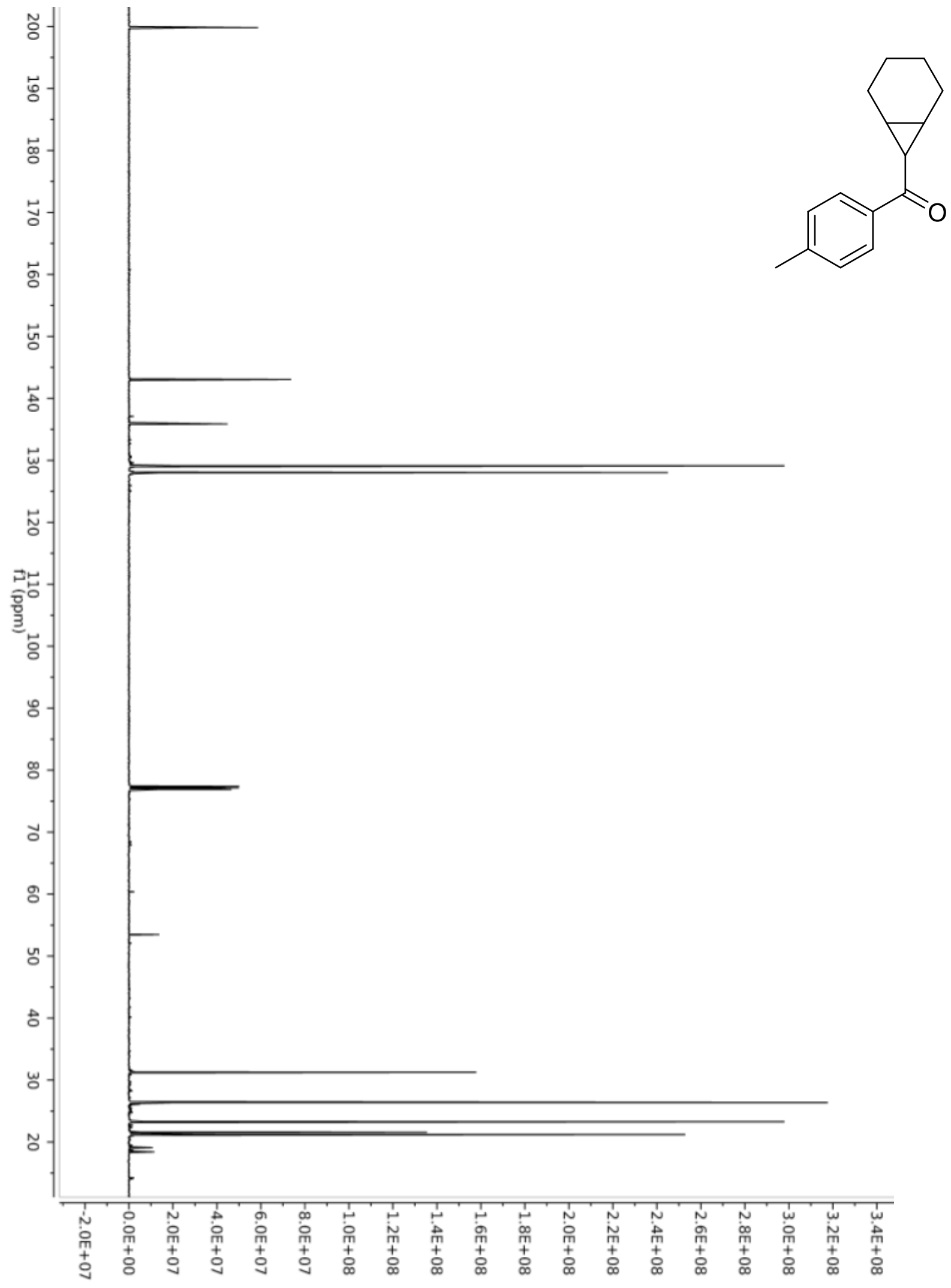

